\title{
Prognostic Value of a CCR5 Defective Allele in Pediatric HIV-1 Infection
}

\author{
Maria Luisa Romiti ${ }^{1}$, Claudia Colognesi ${ }^{2}$, Caterina Cancrini ${ }^{1,3}$, \\ Antonio Mas ${ }^{4}$, Monica Berrino ${ }^{5}$, Francesca Salvatori ${ }^{2}$, Paola Orlandi ${ }^{1}$, \\ Marianne Jansson ${ }^{6}$, Elvia Palomba ${ }^{7}$, Anna Plebani ${ }^{8}$, Jose M. Bertran', \\ Manuel Hernandez', Maurizio de Martino ${ }^{10}$, Antonio Amoroso ${ }^{11}$, \\ Pier Angelo Tovo ${ }^{7}$, Paolo Rossi ${ }^{1,3}$, Teresa Espanol ${ }^{9}$, and Gabriella Scarlatti ${ }^{2}$ \\ ${ }^{1}$ Division of Immunology and Infectious Diseases, Children's Hospital Bambino \\ Gesù, University of Rome Tor Vergata, Rome, Italy ${ }^{2}$ Unit of Immunobiology of \\ HIV, DIBIT, San Raffaele Scientific Institute, Milan, Italy ${ }^{3}$ Children's Hospital \\ Bambino Gesù, Rome, Italy ${ }^{4}$ Instituto de Salud Carlos III, Madrid, Spain \\ ${ }^{5}$ Transplant Immunology Service, Hospital Molinette, Turin, Italy ${ }^{6}$ Microbiology \\ and Tumorbiology Center, Karolinska Institute, Stockholm, Sweden ${ }^{7}$ Department \\ of Paediatrics, University of Turin, Turin, Italy ${ }^{8}$ Department of Paediatrics, \\ University of Milan, Milan, Italy ${ }^{9}$ Immunology Unit, C.S.Vall d'Hebron, Barcelona, \\ Spain ${ }^{10}$ Department of Pediatrics, University of Florence, Italy ${ }^{11}$ Genetic Service, \\ Children's Hospital, University of Trieste, Trieste, Italy \\ Communicated by H. Wigzell. Accepted November 19, 1999.
}

\begin{abstract}
Background: A deletion of 32 base pairs in the CCR5 gene ( $\triangle 32$ CCR 5$)$ has been linked to resistance to HIV-1 infection in exposed adults and to the delay of disease progression in infected adults.

Materials and Methods: To determine the role of $\triangle 32$ CCR5 in disease progression of HIV-1 infected children born to seropositive mothers, we studied a polymerase chain reaction in 301 HIV-1 infected, 262 HIV-1 exposed-uninfected and 47 HIV-1 unexposed-uninfected children of Spanish and Italian origin. Infected children were further divided into two groups according to their rate of HIV-1 disease progression: rapid progressors who developed severe clinical and/or immunological conditions within the second year of life, and delayed progressors with any other evolution of disease. Among the latter were the long-term, non-progressors (LTNP) who presented with mild or no symptoms of HIV-1
\end{abstract}

infection above 8 years of age. Viral phenotype was studied for 45 delayed progressors.

Results: No correlation was found between $\Delta 32$ CCR5 and mother-to-child transmission of HIV-1. However, the frequency of the deletion was substantially higher in LTNP, compared with delayed $(p=0.019)$ and rapid progressors $(p=0.0003)$. In children carrying the $\triangle 32$ CCR 5 mutation, the presence of MT-2 tropic virus isolate was associated with a severe immune suppression $(p=0.028)$; whereas, the presence of MT-2 negative viruses correlated with LTNP $(p=0.010)$.

Conclusions: Given the rapidity and simplicity of the assay, the $\triangle 32 C C R 5$ mutation may be a useful predictive marker to identify children with delayed disease progression who, consequently, may not require immediate antiretroviral treatment.

\section{Introduction}

More than $90 \%$ of Human Immunodeficiency Virus type 1 (HIV- 1 ) infection in children is acquired by mother-to-child transmission (1). Approximately one-third of
HIV-1 infected children born to seropositive mothers progress rapidly during the first 2 years of life toward overt Acquired Immunodeficiency Syndrome (AIDS). Each year thereafter, 5 to $6 \%$ of children develop severe 
symptoms. Only $15 \%$ of children remain asymptomatic by 5 years of age and approximately $4 \%$ after 8 years of age (2). Rapid progressors usually retain high plasma viral load from early age $(3,4)$ and often harbor viruses with rapid replicative and syncytium-inducing capacity $(5,6)$.

Recently, the chemokine receptors were identified as the essential coreceptors for HIV-1 entry into CD $4^{+}$cells (7-10): CXCR4 for T-cell line tropic HIV-1 isolates and CCR5 for those replicating solely in primary peripheral blood mononuclear cells (PBMC). A 32 base-pair (bp) deletion of the CCR5 gene ( 432 CCR5), when expressed in both alleles, was suggested to protect exposed adults from infection with HIV-1 (11-14). However, it was repeatedly shown that homozygous carriers can be infected, presumably with CXCR4dependent viruses $(11,12,14)$. The heterozygous form of the mutation has been correlated with delayed disease progression in HIV-1 infected adults $(15,16)$. In particular, a significantly higher prevalence of $\triangle 32$ CCR5 heterozygous carriers was observed in HIV-1 infected adults long-term non-progressors (LTNP), compared with the general Caucasian population $(13,15,17,18)$. Controversial data were recently reported on the role of the $\triangle 32$ CCR5 mutation in different pediatric cohorts (19-22).

In this study, we investigated the prevalence of the $\triangle 32$ CCR 5 mutation in a cohort of 563 children born to HIV-1 seropositive mothers. We describe a significant correlation with disease progression: LTNP show a 19.7-fold higher frequency of carrying the deletion than rapid progressors. The absence of correlation with transmission suggests that $\triangle 32$ CCR5 heterozygous mutation is not relevant in mother-to-child transmission of HIV-1, as has been suggested for HIV-1-exposed adults.

Address correspondence and reprint requests to: Gabriella Scarlatti, Unit of Immunobiology of HIV, DIBIT, San Raffaele Scientific Institute, Via Olgettina 58, 20132 Milan, Italy. Phone: 39-02-2643-4906; Fax: 39-02-26434905; E-mail: scarlatti.gabriella@hsr.it

This study was conducted in co-operation with the European Concerted Action, European Shared Cost Project Group and the Italian Register for HIV Infection in Children.

\section{Materials and Methods}

\section{Patients}

The group studied was composed of 610 children of Spanish and Italian origin, born before 1995. 563 of the children (262 HIV-1 uninfected and 301 HIV-1 infected) were born to HIV-1 seropositive mothers who had not undergone any antiretroviral treatment to prevent transmission, because these treatments were not yet in use. Children were enrolled from birth in an Italian study on mother-to-child transmission, or were identified as infected at various ages and were monitored at several pediatric centers in Spain, or Northern and Central Italy through the Italian Register of HIV-1 Infection in Children. 47 children born to HIV-1 seronegative mothers were randomly selected from two outpatient clinics in Northern and Central Italy.

Clinical and immunological staging of the HIV-1 infected children was defined according to the revised classification system of the Centers of Disease Control (CDC) (23). The HIV-1 infected children were divided according to the rate of disease progression on the basis of previously published guidelines $(2,24)$. Rapid progressors had an onset of severe clinical manifestations (CDC category C) and/or profound immune suppression (CDC category 3 ) within the first 2 years of life. Children with any other disease evolution were defined as delayed progressors. A well-defined group of LTNP, who presented with no or mild HIV-1 associated signs or symptoms (CDC categories $\mathrm{Nl}$ and Al) above 8 years of age, was also included in the delayed progressors group. The age of the children with delayed disease progression ranged from 2 to 16 years $($ mean $=$ 9.1 years). None of the children was treated with protease-inhibitors at the moment of study.

Identification of $\Delta 32$ CCR5 Deletion by Polymerase Chain Reaction (PCR)

The PBMC of the children were tested for the $32 \mathrm{bp}$ deletion of the CCR 5 gene by PCR. Genomic DNA was obtained by lysis of 2 million PBMC, as previously described (25). Four different PCR approaches, processed in four different laboratories, were used to assay the samples.

In laboratory n.l (University of Tor Vergata, Rome, Italy), the CCR5 sequence 
was amplified with a nested PCR, using the outer primers CKR5.1 (5'-CCCAGGAATCATCTTTAC-3') and CKR5.5 (5'-CTGTGCCTCTTCTTCTCA-3'), and the inner primers CKR5.3 (5'-GCAGTCCTCATTTTCCAT-3') and CKR5.4 (5'-GCCTCTTCTTCTCATTTC-3'). Lysed PBMC were amplified with outer primers at $94^{\circ} \mathrm{C}$ for $5 \mathrm{~min}$ and, then for $25 \mathrm{cy}$ cles at $94^{\circ} \mathrm{C}, 45 \mathrm{sec} ; 58^{\circ} \mathrm{C}, 45 \mathrm{sec} ; 72^{\circ} \mathrm{C}, 45 \mathrm{sec}$; and $72^{\circ} \mathrm{C}, 10 \mathrm{~min}$. Thereafter, $1 / 20$ of the outer product was amplified for 30 cycles with inner primers at the same cycling conditions.

In laboratory n.2 (DIBIT, San Raffaele Scientific Institute, Milan, Italy), the CCR5 sequence was amplified with the outer primer set KR5fw.1 (5'-TTCAATGTAGACATCTATGTAGGC-3') and KR5rv.1 (5'-AGCCATGTGCACAACTCTGACTGG-3'), and the inner primer set KR5fw.3 (5'-GTCTTCATTACACCTGCAGCTCTC-3') and KR5rv.2 (5'-GTCCAACCTGTTAGAGCTACTGC-3'). Cycling conditions were the following for both set of primers: denaturation at $94^{\circ} \mathrm{C}$ for 2 min was followed by 25 cycles of $15 \mathrm{sec}$ at $95^{\circ} \mathrm{C}, 30 \mathrm{sec}$ at $55^{\circ} \mathrm{C}$, and $30 \mathrm{sec}$ at $72^{\circ} \mathrm{C}$ each, and a final extension at $65^{\circ} \mathrm{C}$ for $5 \mathrm{~min}$.

In laboratory n.3 (Transplant Immunology Service, Turin, Italy), the CCR 5 sequence was amplified with the primer set CKR5-ampA (5'GGTGGAACAAGATGGATTAT-3') and CKR5ampB (5'-CATGTGCACAACTCTGACTG-3'). DNA was amplified, after $95^{\circ} \mathrm{C}$ for $5 \mathrm{~min}$, for 35 cycles at $94^{\circ} \mathrm{C}, 60 \mathrm{sec} ; 60^{\circ} \mathrm{C}, 110 \mathrm{sec} ; 72^{\circ} \mathrm{C}, 60$ sec; and $72^{\circ} \mathrm{C}, 5 \mathrm{~min}$.

In laboratory n.4 (Instituto de Salud Carlos III, Madrid, Spain), the amplification of the CCR5 gene was carried out using the specific primers CCR-5D (5'-CCTGGCTGTCGTCCATGCTG-3') and CCR-5U (5'-CCAGCAGCGGCAGGACCAGC-3'). Lysed PBMC were amplified at $94^{\circ} \mathrm{C}$ for $5 \mathrm{~min}$ and, then, for 35 cycles at $94^{\circ} \mathrm{C}$ for $30 \mathrm{sec} ; 58^{\circ} \mathrm{C}, 1 \mathrm{~min} ; 72^{\circ} \mathrm{C}, 1 \mathrm{~min}$; and a final extension at $72^{\circ} \mathrm{C}, 1 \mathrm{~min}$.

The respective PCR products were resolved in $6 \%$ or $12 \%$ polyacrylamide gel or $1.8 \%$ SEPARIDE gel matrix (Gibco, Paisley, U.K.) and visualized by ethidium bromide stain. Samples sent blind to the different laboratories gave identical results.

\section{Viral Phenotype Characterization}

The phenotype of 109 HIV-1 isolates (from 1 to 7 isolates for each child) obtained from 10 LTNP and 35 delayed progressors during a mean follow-up time of 30 months (range 3 to 93 months) was characterized as previously described (26). Briefly, activated PBMC $\left(1 \times 10^{6}\right)$ infected with each viral isolate were co-cultured with $3 \times 10^{6}$ MT- 2 cells or Jurkat-Tat cells. The cells were observed for syncytia formation twice a week and the culture supernatants were tested for HIV-1 p24 antigen production (27). Viral isolates replicating in both cell lines and producing syncytia in MT- 2 cells were defined as MT-2 positive; those replicating only in Jurkat-Tat as MT-2 negative.

\section{Statistical Analysis}

The genetic data were analyzed using ChiSquare test with Yates' correction for contiguity or with Fisher's exact test for groups with less than 15 individuals.

\section{Results}

CCR5 Genotype Does Not Predict HIV-1 Mother-tochild Transmission

The frequency of the $\triangle 32$ CCR5 mutation, homozygous and heterozygous together, was $8.19 \%$, with 50 carriers out of 610 children tested (Table 1). Twenty-five out of 301 (8.3\%) HIV-1 infected children born to seropositive mothers carried a $\triangle 32$ CCR 5 mutation. Similarly, 22 out of $262(8.39 \%)$ HIV-1 uninfected children born to seropositive mothers, and 3 out of $47(6.38 \%)$ HIV-1 unexposed-uninfected children had the same mutation. No "at risk" mother-child pairs had undergone any antiretroviral therapy. The homozygous mutation was detected in one HIV-1 infected and one exposed-uninfected child (over all frequency: $0.3 \%$ ). No significant differences were observed between the Spanish and the Italian cohorts. Thus, the presence of a $\triangle 32$ CCR 5 mutation does not seem to confer protection from infection in mother-to-child transmission of HIV-1.

\section{CCR5 Genotype Correlates with Disease Progression}

HIV-1 infected children were further subdivided according to the course of disease progression: 72 were rapid progressors and 229 delayed progressors; among the latter, 22 were LTNP. The frequency of the $\triangle 32$ CCR 5 deletion was 7.59-fold higher in children with delayed disease progression (Table 2). In particular, 
Table 1. Defective CCR5 allele in HIV-1 infected and uninfected children*

\begin{tabular}{|c|c|c|c|c|}
\hline \multirow[b]{2}{*}{ Origin } & \multicolumn{2}{|c|}{ HIV-1 Uninfected Children } & \multirow[b]{2}{*}{ HIV-1 Infected Children } & \multirow[b]{2}{*}{ Total } \\
\hline & Exposed & Unexposed & & \\
\hline Italy & $14^{+} / 172(8.13 \%)$ & $3 / 47(6.38 \%)$ & $20^{+} / 254(7.87 \%)$ & $37 / 473(7.82 \%)$ \\
\hline Spain & $8 / 90(8.88 \%)$ & n.d. & $5 / 47(10.64 \%)$ & $13 / 137(9.48 \%)$ \\
\hline Total & $22^{+} / 262(8.39 \%)$ & $3 / 47(6.38 \%)$ & $25^{+} / 301(8.3 \%)$ & $50 / 610(8.19 \%)$ \\
\hline \multicolumn{5}{|c|}{$\begin{array}{l}\text { * Number of child carriers of the defective CCR5 allele out of total number of children tested. In parenthesis is the frequency } \\
\text { of occurrence. Mean value of defective CCR5 allele of the HIV-1 uninfected children: in total } 25 / 309(8.09 \%) \text {, in Italy } \\
17 / 219(7.76 \%) \text { and Spain } 8 / 90(8.88 \%) \text {. n.d. means not done. } \\
{ }^{+} \text {Only one child of this group was a carrier of a homozygous deletion of the CCR5 gene. }\end{array}$} \\
\hline
\end{tabular}

only 1 out of 72 rapid progressors $(1.38 \%)$ displayed the deletion, compared with 24 of the 229 delayed progressors $(10.48 \% ; p=0.0288)$. The impact of the $\triangle 32$ CCR5 deletion on the evolution of HIV-1 disease was even more evident when the group of LTNP was compared with the rapid progressors. Of the former, 6 of the 22 children $(27.27 \%)$ carried the mutation. Thus, LTNP have a 19.7-fold higher frequency of a $\triangle 32$ CCR5 mutation when compared with rapid progressors $(p=0.0003)$. The only homozygous carrier of $\triangle 32$ CCR 5 had a delayed disease progression displaying CDC A2 category at 4 years of age, a progression of clinical symp-toms (CDC B2) at 7 years and a further decline of the CD4 cell counts at 11 years (CDC B3).

To further analyze the impact of the $\Delta 32$ CCR5 mutation on disease progression in longterm surviving children, we considered the group of delayed progressors above 8 years of age separately. In this group of 149 children, which include also LTNP, we describe a strong correlation ( $p=0.0012)$ between the presence of the mutation and no or mild development of HIV-associated symptoms/signs (i.e. CDC category $\mathrm{Nl}$ or $\mathrm{Al}$; data not shown). No such correlation was observed in the group of children below 8 years of age, further supporting our data that the presence of the mutation favors a longer survival with milder disease progression.

No substantial differences were found in the frequency of the $\triangle 32$ CCR 5 gene between rapid progressors of Spanish and Italian origin $(1.78 \%$ vs. 0$)$. Delayed progressors of the Spanish group had a higher, though not statistically significant, frequency of the $\triangle 32$ CCR 5 mutation than those of the Italian group $(16.13 \%$ vs. $9.59 \%)$. The age of the 18 delayed progressors with the $\triangle 32$ CCR5 deletion, excluding the LTNP, ranged between 2 and 12 years (mean age: 7.3 years), of whom half were above 8 years of age. The mean age was lower in Span-

Table 2. Defective CCR5 allele in HIV-1 infected children ${ }^{\ddagger}$

\begin{tabular}{llll}
\hline Origin & Rapid Progressors & Delayed Progressors & LTNP $^{\mathrm{II}}$ \\
\hline Italy & $1 / 56(1.78 \%)$ & $19^{+} / 198(9.59 \%)$ & $6 / 22(27.27 \%)$ \\
Spain & $0 / 16$ & $5 / 31(16.13 \%)$ & n.d. \\
Total & $1 / 72(1.38 \%)$ & $24^{+} / 229(10.48 \%)^{* *}$ & $6 / 22(27.27 \%)^{++}$
\end{tabular}

${ }^{\ddagger}$ Footnotes as in Table 1.

${ }^{\S}$ Delayed progressor include any category excluded the rapid progressors.

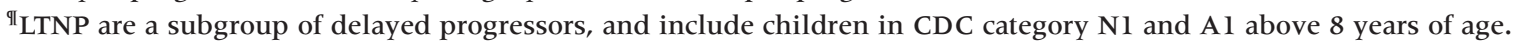

${ }^{* *}$ Chi square: Rapid progressors vs. delayed progressors $p=0.0288$.

${ }^{++}$Chi square: Rapid progressors vs. LTNP $p=0.0003$. 
ish delayed progressors (5.2 years) than in Italian children ( 9.3 years).

\section{Viral Tropism in Children with Delayed Disease Progression}

In a group of 45 progressively followed children with delayed disease progression $(n=35)$ or LTNP $(n=10)$, we characterized the viral phenotype, defined as the tropism of the viral isolate for MT-2 cells. Altogether, at the last timepoint of the follow-up we isolated from 17 $(37.77 \%)$ children a MT-2 positive virus and from $28(62.22 \%)$ a MT-2 negative virus. When we compared the viral phenotype with disease progression, we observed that only one of the 10 LTNP, but 16 of the 35 delayed progressors carried a MT-2 tropic viral isolate (Fig. $1 ; p=$ 0.0921 ; follow-up time 10.75 vs. 8.1 years of age, for LTNP vs. delayed progressors, respectively). Specifically, during the follow-up, the group of delayed progressors showed a switch from MT-2-negative to -positive viral isolates at a mean age of 5 years in 9 cases (range: 2.25 to 11.17 years of age). In 7 children, a MT-2 tropic virus was isolated since the age of first virological follow-up at a mean age of 7.2 years (data

\begin{tabular}{|c|c|c|c|}
\hline \multirow{3}{*}{ Disease progression } & Children's & \multirow{2}{*}{\multicolumn{2}{|c|}{ Viral phenotype }} \\
\hline & CCR5 genotype & & \\
\hline & & MT-2 - & MT-2+ \\
\hline \multirow{2}{*}{ LTNP (10) } & WT & 5 & 1 \\
\hline & $\Delta 32$ & 4 & 0 \\
\hline \multirow{2}{*}{ Delayed Prog. (35) } & WT & 19 & 13 \\
\hline & $\Delta 32$ & 0 & 3 \\
\hline$p$ value & & 0.0104 & n.s. \\
\hline
\end{tabular}

Fig. 1. Association between viral phenotype and disease progression. The presence $(\Delta 32)$ or absence (WT) of the $\Delta 32$ deletion of the CCR 5 gene and viral phenotype according to growth $(+)$ or no growth $(-)$ in MT-2 cells of the viral isolate obtained at the last time-point during follow-up of the children is shown for LTNP (long-term-non progressors) and delayed progressors. The number of observations/patients are in parentheses. Statistics expressed as $p$ value, n.s. = not significant. not shown). Nineteen delayed progressors and 9 LTNP still carried a MT-2 negative viral isolate at a mean age of 8.7 years (range 3.08 to 15.33 years) and 10.7 years (range: 9.58 to 12.25 years), respectively. Only one LTNP developed a MT-2 tropic virus at an age of 6.7 years, but had not yet progressed in disease after 3.5 years from the phenotypic switch.

Antiretroviral therapy did not correlate with MT-2 tropism, as approximately threequarters of the children, independent of age, were treated with reverse-transcription inhibitors. Patients began therapy at a mean age of 4.18 years (range: 0.5 to 13 years), with a mean duration of 4.5 years (range: 1 to 9 years). None of the children had started therapy with protease inhibitors. Untreated children had reached a mean age of 9 years (range: 4 to 14 years).

\section{CCR5 Genotype and Viral Tropism Correlate with Disease Progression}

Comparison of the viral phenotype with CCR5 genotype showed that a similar frequency of MT-2 tropic viruses was isolated from children with the wild type CCR 5 gene (14/38 children; $36.84 \%$ ) and from those with the $\triangle 32$ CCR 5 mutation (3/7 children; $42.86 \%$; Fig. 2 ). The mean age of follow-up of the children carriers of the $\triangle 32$ CCR5 gene and of those with the wild type gene was similar (9.3 years vs. 8.6 years, respectively). Thus, no clear correlation was observed between viral phenotype and $\triangle 32$ CCR5 in the infected children with delayed disease progression including LTNP.

The analysis of the same parameters according to different disease progression showed that 4 of 9 LTNP who harbored a MT2 negative virus carried the $\triangle 32$ CCR 5 deletion; whereas, none of the 19 delayed progressors did (Fig. $1 ; p=0.01$ ). This correlation was also maintained when only children above 8 years of age were included $(p=0.045)$ to avoid bias due to length of follow-up (data not shown). No such correlation was observed for children who harbored a MT-2 tropic virus. This may indicate that the presence of the genetic mutation together with a less aggressive virus can prolong symptom-free disease in infected children.

The viral phenotype was associated with $\mathrm{CD}^{+}$cell levels. Indeed, a MT-2 tropic virus was recovered only in 5 out of 23 children 


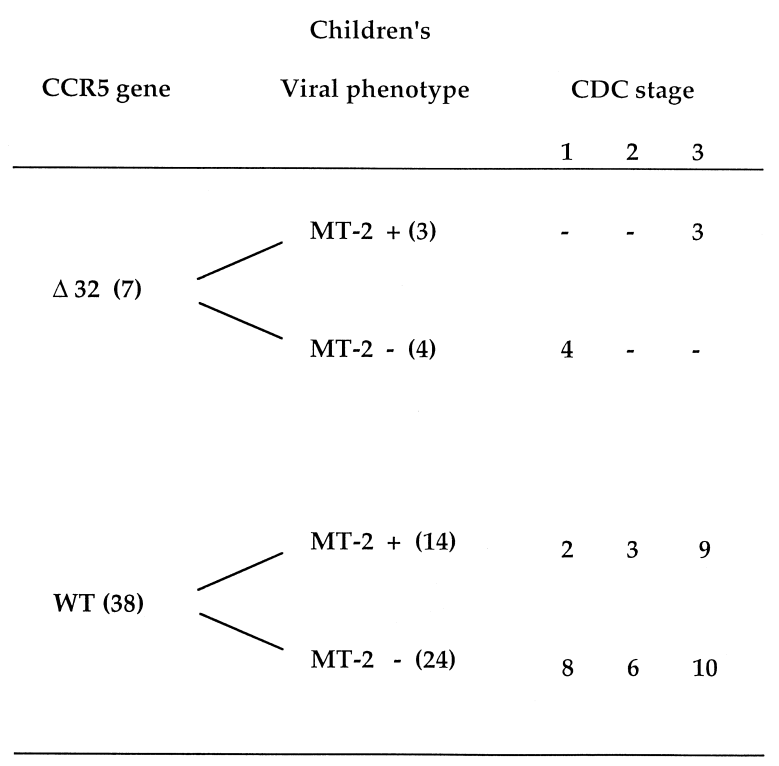

Fig. 2. Characteristics of HIV-1 infected children with delayed disease progression. In the figure are indicated: The phenotype, defined as growth $(+)$ or no growth $(-)$, in MT-2 cells of the viral isolate obtained at the last time-point during follow-up of the children and the CDC stage, as immunological classification according to the 1994 Revised Classification of the Centers of Disease Control, are shown for patients with the presence $(\Delta 32)$ or absence (WT) of the $\Delta 32$ deletion of the CCR5 gene.

$(21.74 \%)$ with $\mathrm{CD} 4^{+}$cell levels $>15 \%$ (CDC categories 1 and 2), compared with 12 out of 22 children $(54.54 \%)$ with severe immunodeficiency (i.e. with $\mathrm{CD} 4^{+}$cells $<15 \%$; CDC category $3 ; p=0.05)$. Interestingly, this correlation became statistically stronger when the children were grouped according to the CCR5 genotype. MT-2 viral tropism was significantly correlated with severe immunodeficiency in children carrying the $\Delta 32$ CCR 5 deletion (Fig. 2), but not in those with the wild type gene. Indeed, all children carriers of a MT-2 tropic viral isolate and the deleted gene were classified as CDC category $3(p=0.028)$, only 9 out of 19 $(47.37 \%)$ of those with the wild type gene. Thus, the $\triangle 32$ CCR5 deletion together with a syncytium-inducing virus correlated with development of severe immunodeficiency.

\section{Discussion}

We show that the presence of the $\triangle 32$ CCR $5 \mathrm{mu}$ tation, either heterozygous or homozygous, is not associated with transmission of HIV-1 from the mother to the child. We found only 2 children that were homozygous carriers of the mutation and one of them acquired the infection. Our study is in agreement with other recently published reports on pediatric cohorts collected in different countries (19-21). Accordingly, Misrahi et al. (20) described only one homozygous carrier of the $\triangle 32$ CCR 5 mutation, an uninfected child, in a cohort of 512 French children born to HIV-1 positive mothers. Of interest is the difference with several studies, which demonstrated that the homozygous $\Delta 32$ CCR5 mutation correlated with protection from HIV-1 infection in exposed adults (11-13). However, infection of $\triangle 32$ CCR 5 homozygous adult carrier was repeatedly described and was probably ascribed to transmission of the MT-2 tropic virus capable of using the CXCR4 receptor $(11,12,14)$. Although we isolated a MT-2 tropic virus from the PBMC of a child with the homozygous CCR5 mutation, no conclusions can be drawn on the phenotype of the infecting virus at birth due to lack of early samples. Further studies are needed to define the relevance of a $\triangle 32$ CCR 5 mutation in favoring mother-to-child transmission of MT-2 tropic isolates.

It has been suggested that HIV-1 perinatal transmission is linked to viral tropism for CCR5 (28). Overwhelming evidence indicates that a great proportion of neonates are infected with MT-2 negative viruses, which are viruses capable of using the CCR5 receptor only (27). However, we previously showed that mothers harboring a MT-2 tropic virus can transmit to their child either a virus with the same characteristics or a MT-2 negative virus (26). MT-2 positive viral isolates were identified as those able to use the CXCR4 as a coreceptor for entry, though most of these viruses keep the capacity to also use CCR5 (27). Better information will clarify the preferential transmission of CCR5dependent viruses and, thus, assess the clinical relevance of developing therapies aimed to interfere with viral entry.

Our data show that the heterozygous $\Delta 32$ CCR5 gene is significantly associated with delayed disease progression in HIV-1 infected children of Spanish and Italian origin. In particular, LTNP have a significantly higher frequency of this mutation than rapid progressors. Similarly, Misrahi et al. (20) found an association of the mutation with delayed disease progression in HIV-1 perinatally infected children 
and reported that approximately $50 \%$ of those with the $\triangle 32$ CCR5 heterozygous mutation, but only $11 \%$ of those without the mutation, were still asymptomatic (CDC category $\mathrm{N}$ or $\mathrm{A}$ ) at 8 years of age. However, most children were below 7 years of age and the persistence of the protective effect of the $\triangle 32$ CCR 5 heterozygous mutation had not been studied. Here, we show that LTNP have a higher frequency of the mutated gene compared with symptomatic children surviving above 8 years of age. Still, not all published reports on pediatric cohorts found a correlation of the mutated gene with delay of disease progression $(21,29)$. This may be attributed to different sized study populations and to the use of different parameters for the classification of disease in the children. As suggested by previously published epidemiological data (2), we rigorously considered LTNP children in CDC category $\mathrm{Nl}$ and Al after 8 years of age.

Although we do not demonstrate a clear correlation between the $\triangle 32$ CCR 5 mutation and viral tropism, our study shows that, in child carriers of the $\triangle 32$ CCR 5 mutation, the presence of MT-2 tropic virus isolates was significantly associated with a severe immune suppression (CDC category 3); whereas, the presence of MT-2 negative viruses correlated with LTNP. Thus, the genetic mutation appears to have a protective effect against HIV-1 disease progression in individuals carrying less aggressive viruses, such as MT-2 negative virus isolates. Our data are in agreement with those published by Bratt et al. (30) who described the synergistic effects of viral phenotype and CCR5 genotype in disease progression. Adult HIV-1 infected carriers of the heterozygous $\triangle 32$ CCR 5 gene and MT-2 negative viruses had the lowest prevalence of AIDS, the highest $\mathrm{CD} 4^{+}$lymphocyte count, and the lowest plasma viral load. Recently, Buseyene et al. (22) demonstrated in HIV-1 infected children above 8 years of age the beneficial role of the heterozygous $\triangle 32$ CCR5 gene on the percentage of $\mathrm{CD} 4^{+} \mathrm{T}$ cells, as we did, as well as on viral load.

In conclusion, our data strongly suggest that the heterozygous $\triangle 32$ CCR 5 deletion does not prevent HIV-1 infection in perinatally exposed children, but plays a protective role against disease progression in infected children. A deletion in the CCR5 gene may result in a lower efficiency of replication of viruses capable of using this coreceptor and, as a consequence, to delayed disease progression in vivo. Still, caution should be taken and the possible adverse effects of $\triangle 32$ CCR 5 promoting the appearance of viruses with aggressive phenotype should be considered. The rapidity and simplicity of the assay for the detection of the mutation favors the use of this parameter as a marker to identify children with delayed diease progression who, consequently, do not require immediate antiretroviral treatment.

\section{Acknowledgments}

We thank for advice and counsel all participants of the European Concerted Action and Shared Cost Group, and for the assistance of the clinician involved. The Italian Register for HIV Infected Children participants in the study included: Camilla Ajassa (Policlinico Umberto I, Rome, Italy), Paola Dallacasa (University of Bologna, Italy), Desire Caselli (IRCCS Policlinico S. Matteo, Pavia, Italy), Adriano Corrias (University of Cagliari, Italy), Marzia Duse (University of Brescia, Italy), Pasquale Ferrante (University of Bari, Italy), Gabriele Ferraris ( $\mathrm{H}$. Mangiagalli, Milan, Italy), Gian Luca Forni (E.O. Hospital Galliera, Genoa, Italy), Carlo Fundarò (University Cattolica, Rome, Italy), Clara Gabiano (University of Turin, Italy), Luisa Galli (University of Florence, Italy), Carlo Giaquinto (University of Padua, Italy), Domenico Larovere (Hospital "Giovanni XXIII", Bari, Italy), Susanna Livadiotti (Hospital Bambino Gesù, Rome, Italy), Paola Marchisio (Hospital L. Sacco, Milan, Italy), Andrea de Maria (Institute Gaslini, Genoa, Italy), Antonio Mazza (Children Hospital, Trento, Italy), Anna Plebani (University of Milan, Italy), Laura Rancilio (H. Mangiagalli, Milan, Italy), Alessandra Viganò (University of Milan, Italy), and Vincenzo Zuccotti (Hospital S. Paolo, Milan, Italy). This study was funded by grants from European Community, BIOMED 2 Project on "Attenuated viruses and protective immune response in European LTS HIV infected children" (grant numbers BMH4-97-2262 and BMH1-CT94-1492), and Istituto Superiore di Sanità grant numbers 9608-11 (P.R.), 20.A.20 (PA.T.) and 40A.0.93 (G.S.). F.S. is a recipient of a fellowship from the Istituto Superiore di Sanità. 


\section{References}

1. Scarlatti G. (1996) Paediatric human immunodeficiency virus type 1 infection. Lancet 348: 863-868.

2. Tovo PA, De Martino M, Gabiano C, et al. (1997) Long-term nonprogressors among children with perinatal HIV-1 infection. J. Acquir. Immune. Syndr. 15: S19-S22.

3. De Rossi A, Masiero S, Giaquinto C, et al. (1996) Dynamics of viral replication in infants with vertically acquired human immunodeficiency virus type 1 infection. J. Clin. Invest. 97: 323-330.

4. Shearer WT, Quinn TC, LaRussa, P, et al. (1997) Viral load and disease progression in infants infected with human immunodeficiency virus type 1. N. Engl. J. Med. 336: 1337-1342.

5. De Rossi A, Pasti M, Mammano F, Ometto L, Giaquinto C, Chieco-Bianchi L. (1991) Perinatal infection by human immunodeficiency virus type 1 (HIV-1): relationship between proviral copy number in vivo, viral properties in vitro, and clinical outcome. J. Med. Virol. 35: 283-289.

6. Scarlatti G, Hodara V, Colognesi C, Beretta A, Albert J, Fenyö E M. (1995) Autologous neutralizing antibody response and virus phenotype in progression of disease of HIV-1 infected children. J. Cell. Biochem. Suppl. 19D: 451.

7. Alkhatib G, Combadiere C, Broder CC, et al. (1996) CC CRK5: a RANTES, MIP-1 $\alpha$, MIP-1 $\beta$ receptor as a fusion cofactor for macrophagetropic HIV-1. Science 272: 1955-1958.

8. Deng H, Liu R, Ellmeier W, et al. (1996) Identification of a major co-receptor for primary isolates of HIV-1. Nature 381: 661-666.

9. Dragic T, Litwin V, Allaway GP, et al. (1996) HIV-1 entry into CD4+ cells is mediated by the chemokine receptor CC-CRK-5. Nature 381: 667-673.

10. Feng Y, Broder CC, Kennedy PE, Berger EA. (1996) HIV-1 entry cofactor: functional cDNA cloning of a seven-transmembrane, G proteincoupled receptor. Science 272: 872-877.

11. O'Brien T, Winkler C, Dean M, et al. (1997) HIV1 infection in a man homozygous for CCR $5 \Delta 32$. Lancet 349: 1219.

12. Theodorou I, Meyer L, Magierowska M, Katlama C, Rouzioux C, Seroco Study Group. (1997) HIV-1 infection in an individual homozygous for CCR5 32. Lancet 349: 1219-1220.

13. Samson M, Libert F, Doranz BJ, et al. (1996) Resistance to HIV-1 infection in caucasian individuals bearing mutant alleles of the CCR-5 chemokine receptor gene. Nature 382: 722-725.

14. Biti R, French R, Young J, Bennetts B, Stewart G, Liang, T. (1997) HIV-1 infection in an individual homozygous for the CCR5 deletion allele. Nature Med. 3: 252-253.
15. Huang Y, Paxton WA, Wolinsky SM, et al. (1996) The role of a mutant CCR5 allele in HIV1 transmission and disease progression. Nature Med. 2: 1240-1243.

16. Dean M, Carrington M, Winkler C, et al. (1996) Genetic restriction of HIV-1 infection and progression to AIDS by a deletion allele of the CKR5 structural gene. Science 273: 1856-1862.

17. Michael NL, Chang G, Louie LG, et al. (1997) The role of viral phenotype and CCR-5 gene defects in HIV-1 transmission and disease progression. Nature Med. 3: 338-340.

18. Stewart G, Ashton L, Biti R, et al. (1997) Increased frequency of CCR-5 $\Delta 32$ heterozygotes among long-term non-progressors with HIV-1 infection. The Australian long-term nonprogressor study group. AIDS 11: 1833-1838.

19. Edelstein R, Arcuino L, Hughes J, et al. (1997) Risk of mother-to-infant transmission of HIV-1 is not reduced in CCR5/ $\triangle 32 \mathrm{ccr} 5$ heterozygotes. J. Acquir. Immune. Syndr. 16: 243-246.

20. Misrahi M, Teglas JP, N'Go N, et al. (1998) CCR5 chemokine receptor variant in HIV-1 mother-to-child transmission and disease progression in children. French Pediadric HIV Infection Study Group. JAMA 279: 277-280.

21. Rousseau C, Just J, Abrams E, Casabona J, Stein Z, King M-C. (1997) CCR5 $\Delta 32$ in perinatal HIV-1 infection. J. Acquir. Immune. Syndr. 16: 239-242.

22. Buseyne F, Janvier G, Teglas JP, et al. (1998) Impact of heterozygosity for the chemokine receptor CCR5 32-bp-deleted allele on plasma virus load and CD4 T lymphocytes in perinatally human immunodeficiency virus-infected children at 8 years of age. J. Infect. Dis. 178: 1019-1023.

23. Centers for Disease Control. (1994) Revised classification system for human immunodeficiency virus enfection in children less than 13 years of age. Morbid. Mortal. Wkly. Rep. 43: 1-10.

24. Martin N, Koup R, Kaslow R, Coffin J, Ammann A, Participants in the Long-Term Survivor Project. (1996) Workshop on perinatally acquired human immunodeficiency virus infection in long-term surviving children: a collaborative study of factors contributing to slow disease progression. AIDS Res. Hum. Retroviruses 12: 1565-1570.

25. Scarlatti G, Lombardi V, Plebani A, et al. (1991) Polymerase chain reaction, virus isolation and antigen assay in HIV-1 antibody positive mothers and their children. AIDS 5: 1173-1178.

26. Scarlatti G, Hodara V, Rossi P, et al. (1993) Transmission of human immunodeficiency virus type 1 (HIV-1) from mother-to-child correlates with viral phenotype. Virology 197: 624-629.

27. Scarlatti G, Tresoldi E, Björndal A, et al. (1997) In vivo evolution of HIV-1 coreceptor usage and sensitivity to chemokine-mediated suppression. Nature Med. 3: 1259-1265. 
28. Ometto L, Zanotto C, Maccabruni A, et al. (1995) Viral phenotype and host-cell susceptibility to HIV-1 infection as risk factors for mother-to-child HIV-1 transmission. AIDS 9: 427-434.

29. Bakshi S, Zhang L, Ho D, Than S, Pahwa S. (1998) Distribution of CCR 532 in human im- munodeficiency virus-infected children and its relationship to disease course. Clin. Diagn. Lab. Immunol. 5: 38-40.

30. Bratt G, Sandstrom E, Albert J, Samson M, Wahren B. (1997) The infleunce of MT-2 tropism on the prognostic implications of the $\Delta 32$ deletion in the CCR5-gene. AIDS 11: 1415-1419. 